\title{
COMO OS ACADÉMICOS SE ADAPTAM A UM ENSINO BASEADO EM PBL NUMA LICENCIATURA TRADICIONAL EM CONTABILIDADE
}

\section{HOW ACADEMICS ADAPT TO PBL TEACHING IN AN ACCOUNTING COURSE}

\author{
Margarida M Pinheiro ${ }^{a}$; Cláudia S Sarrico ${ }^{b}$; Rui A Santiago ${ }^{c}$ \\ a Professora Adjunta, ISCA - Instituto Superior de Contabilidade e Administração, UA - Universidade de Aveiro e GOVCOPP \\ - Unidade de Investigação em Governança, Competitividade e Políticas Públicas, Aveiro; Doutora em Ciências Sociais; Email: \\ margarida.pinheiro@ua.pt \\ ${ }^{b}$ Professora Associada com Agregação do Departamento de Gestão, ISEG-Instituto Superior de Economia e Gestão, UTL - \\ Universidade Técnica de Lisboa e CIPES - Centro de Investigação de Políticas do Ensino Superior; Matosinhos; PhD in \\ Industrial and Business Studies; E-mail: cssarrico@iseg.utl.pt \\ c Professor Associado com Agregação, DCSPT - Departamento de Ciências Sociais, Políticas e do Território, UA - \\ Universidade de Aveiro e CIPES - Centro de Investigação de Politicas do Ensino Superior, Matosinhos; Doutor em \\ Educação; E-mail: rui.santiago@ua.pt
}

\section{Resumo}

O objetivo geral do presente trabalho é o de procurar contribuir para a discussão teórica sobre a forma como a utilização de metodologias PBL produz implicações ao nível das formas de atuar dos docentes no ensino superior profissionalizante. Em termos mais específicos, procuramos perceber (1) que papéis são os docentes chamados a desempenhar; (2) que estratégias específicas são suscetíveis de serem modificadas nas práticas docentes; (3) até que ponto experiências profissionais fora das IES contribuem para desempenhos dissimilares nas atividades pedagógicas dos docentes; e, finalmente, (4) se é razoável a identificação de todos os docentes com métodos emergentes de ensino. O presente trabalho desenvolve-se sob a forma de estudo de caso de uma instituição de ensino superior profissionalizante que assume como seu objeto a disciplina semestral de Simulação Empresarial ministrada no Instituto Superior de Contabilidade e Administração Da Universidade e Aveiro (ISCA-UA). O nosso objeto de análise encontra-se circunscrito aos grupos dos alunos e dos docentes envolvidos, considerando-os como elementos centrais na operacionalização e concretização dos sistemas de ensino-aprendizagem. Permitimo-nos concluir que os estudantes, não previamente identificados com metodologias que reforcem o seu envolvimento na produção do conhecimento, ainda presumem e esperam respostas pré-formatadas dos docentes.

Palavras-chave: Ensino Superior Profissionalizante, Ensino-aprendizagem, PBL. Contabilidade.

\begin{abstract}
The general purpose of this work is to contribute to a theoretical discussion on how PBL methodologies influence the way teachers behave in professional higher education. More specifically, we try to understand (1) the roles teachers are asked to perform; (2) what particular strategies can be subject to changes in teaching methods; (3) to what extent professional experience outside higher education institutions contribute to different performances in teachers pedagogical activities; (4) and, finally, if it is worthwhile the identification of all teachers with emerging teaching methodologies. This paper takes the form of a case study of a professional higher education institution which assumes as object the subject of Business Simulation taught at the Higher Institute for Accounting and Administration of Aveiro University (ISCA-UA). Our study object is circumscribed to the groups of students and teachers involved in the subject, and they are considered as central elements in the functioning and accomplishing of the teachinglearning systems. We rely on the premise that students who have not previously been identified with methodologies that reinforce their involvement with knowledge production are still waiting for pre-formatted answers from teachers. Concerning teachers' teaching strategies, this study reveals that the challenges created by the immersion in PBL environments give rise to epistemological concerns, evidencing a variety of strategies in the way peers cope with PBL environments.
\end{abstract}

Keywords: Vocational Higher Education, Teaching and Learning. PBL, Accounting Program. 


\section{INTRODUÇÃO}

As profundas e rápidas alterações no contexto social e económico mundial implicam a emergência de grandes desafios para as sociedades contemporâneas. De acordo com BAYNE (2007), estas mudanças, aliadas ao crescente desenvolvimento tecnológico e à adaptabilidade e flexibilidade exigidas pelos empregadores, estimulam novas formas de produção e disseminação do conhecimento com consequências, também, para as instituições de ensino superior (IES). Tendo por referência esse contexto, é possível compreender que alguns autores (e.g. BALLANTINE et al., 2008; NIJHUIS et al., 2007) insistam na ideia de que se torna importante repensar paradigmas de ensino e aprendizagem que coloquem a tónica na preparação dos estudantes quando inseridos em situações profissionais reais.

Uma forma sugerida de colmatar a lacuna entre práticas pedagógicas e práticas profissionais é a da mudança de um sistema tradicional de ensino (entendido no sentido socrático de transmissão unívoca de conhecimento do docente para o aluno) para uma metodologia baseada em projetos (project-based learning) ou em problemas (problem-based learning), que passaremos a designar por metodologias PBL. A ideia de valor de fundo das metodologias PBL pressupõe que os seus aspetos mais importantes se prendem com a mudança do centro de interesse do ensino para a aprendizagem, o papel ativo assumido pelo estudante no processamento desta mesma aprendizagem, a resolução de problemas em contexto semelhante ao profissional, o reforço de uma visão interdisciplinar do conhecimento ou o desenvolvimento de competências técnicas, pessoais, sociais e profissionais (e.g. SILÉN e JUHLIN, 2008).

Enquadrados pela problemática apresentada, procuramos perceber e analisar de que forma os propósitos básicos associados às metodologias PBL se relacionam com as formas de atuar dos docentes. Parecendo-nos tal intento demasiado ambicioso, usamos como instrumento de trabalho um estudo de caso único de uma IES profissionalizante motivado pela disciplina de Simulação Empresarial configurada como uma adaptação de metodologias PBL. O nosso objeto de análise encontra-se circunscrito aos grupos dos alunos e dos docentes, considerando-os como elementos centrais na operacionalização e concretização dos sistemas de ensino-aprendizagem. Em termos mais específicos, procuramos explorar a adoção de um curso PBL num ambiente tradicional de ensino, tentando perceber como os docentes se adaptam a mudanças estruturais e com que identidades alternativas se confrontam.

Tendo essa problemática como pano de fundo, várias questões de investigação emergem. Em particular, procuramos perceber: (1) que papéis são os docentes chamados a desempenhar; (2) que estratégias específicas são suscetíveis de serem modificadas nas práticas docentes; (3) até que ponto experiências profissionais fora das IES contribuem para desempenhos dissimilares nas atividades pedagógicas dos docentes; e, finalmente, (4) se é razoável a identificação de todos os docentes com métodos emergentes de ensino.

Começando por refletir sobre os processos de ensino e aprendizagem no ensino superior profissionalizante português, o artigo evolui para a análise dos papéis que os docentes $\mathrm{PBL}$ são chamados a desempenhar e para as potenciais estratégias usadas por estes. Em seguida, e após apresentado o estudo de caso, são descritos os procedimentos adotados no contorno metodológico da investigação. Finalmente, são expostos e discutidos os resultados obtidos, terminando o artigo com alguns comentários finais. 


\section{PARADIGMAS DOS PROCESSOS DE ENSINO E APRENDIZAGEM E METODOLOGIAS PBL NO CONTEXTO DO ENSINO PROFISSIONALIZANTE PORTUGUÊS}

O sistema educativo superior português é caracterizado por uma dupla identificação: universitário e politécnico. Enquanto o ensino universitário assume uma postura de maior independência institucional e social, conducente a uma atitude mais reflexiva que permite projetar em tempo futuro os conhecimentos do tempo presente, o ensino politécnico mergulha, constantemente, nas necessidades manifestadas pela sociedade que o rodeia, acompanhando o ritmo da mesma e conjugando, em tempo real, as aprendizagens. Encontramos, assim, duas lógicas distintas: no ensino universitário, e em tempos sequenciais, distinguimos o saber e o saber fazer, enquanto no ensino politécnico coincidem, num mesmo tempo, o saber, o saber fazer e o fazer (MAGALHÃES e AMARAL, 2000). Portanto, falar de ensino superior politécnico em Portugal é intensificar a atenção dada às relações empresariais entre parceiros externos e IES profissionalizantes. E é precisamente a problemática da transição de estudantes para ambientes profissionais que nos faz assistir a um desfocar de fronteiras entre a atividade académica e a atividade profissional.

Podemos afirmar que, atualmente, não só o tipo de conhecimento que se quer produzir é diferente do herdado das gerações anteriores (porque se requer mais variado, não sistemático, reflexivo, aberto às necessidades percebidas da sociedade e das empresas e multidisciplinar), como também é afetada a forma como este mesmo conhecimento é produzido (MAGALHÃES, 2004). A focalização num perfil do estudante capaz de articular aspetos cognitivos com aspetos não cognitivos, lança às IES profissionalizante o desafio de formar pessoas mais diretamente vocacionadas para o mercado de trabalho, com uma ênfase mais clara na aquisição de competências profissionais, mas também com competências valorativas dos indivíduos em si, a par de competências de socialização (GIBBONS et al., 1994). Nesse processo, a palavra-chave é a transversalidade dos vários elementos que preparem os diplomados para as diversas áreas profissionais.

Da reflexão sobre esquemas alternativos de ensino-aprendizagem no ensino superior e das sinergias resultantes de diferentes dinamismos ideológicos e organizacionais, foi possível fundamentar práticas baseadas em metodologias PBL como suscetíveis de darem respostas às novas pedagogias profissionais (MUSAL et al., 2003). Como estratégia de ensino, a metodologia PBL centra-se, em primeiro lugar, na apresentação de cenários contextualizados de problemas profissionais, antecipadamente identificados com situações reais com que os futuros diplomados terão de se confrontar (BARROWS, 1999; DAHLGREN e OBERG, 2001). O objetivo básico do processo é o do reconhecimento das necessidades de aprendizagem, objetivo este que se pretende que leve o aluno a assumir uma participação ativa na constução do conhecimento que necessita para dar resposta às necessidades reconhecidas (BLIGH e RANKIN, 1999; MARGETSON, 1998).

De acordo com vários autores (e.g., KIRSCHNER et al., 1997), a aprendizagem tem lugar quando há uma participação ativa e empenhada do aprendente, que reconstrói o conhecimento, moldando-o às suas necessidades e imagem. Tal conceito pressupõe uma construção ativa de significados para quem aprende, tornando-a, simultaneamente, mais duradoura pela interiorização que promove. A construção da aprendizagem, personalizada para cada aluno para um propósito e com um propósito, implica que cada um a possa entender de forma diferente do outro, sem que tal individualização iniba os resultados da aprendizagem. Este conceito feito à 
medida estimula, por um lado, competências sociais de crescimento intelectual e pessoal e, por outro, torna tais competências mais eficazes. De acordo com esta metodologia, serão os alunos que pesquisarão as respostas às questões que os próprios colocam, selecionando o que pode, efetivamente, responder às suas dúvidas e justificando as conclusões encontradas.

Aestrutura metodológica assim apontada parece realçar aideia, mais ou menos consensual, de que é importante ir ao encontro dos interesses dos alunos. No entanto, esta relação não pode ser analisada de uma forma unidirecional e, em extremo, promover uma versão radical em que cada aluno avança de acordo com os seus interesses. De facto, se é importante motivar os alunos, também não se pode balizar o progresso curricular pelos sentimentos positivos que os mesmos demonstrem, sob pena de se tolher a capacidade de abstração e, consequentemente, as aprendizagens. Esta orientação dá, assim, lugar, a três domínios de aprendizagem: o cognitivo, o das significações pessoais e o do saber fazer. Brockbank e Mcgill (1998) argumentam que a participação ativa do aprendente na construção das suas aprendizagens, acompanhada de autoavaliação e de avaliação formativa, com todo o seu potencial reflexivo, permitem aprendizagens duradouras e solidamente construídas, que se estendem muito para além de um determinado momento temporal. Com este tipo de envolvimento, que busca energia na permanente dialética das relações entre os estudantes e os seus pares, entre os estudantes e os seus professores e no conhecimento construído e permanentemente estimulado, reflete as aprendizagens como expressão de um sistema social (e.g., TAVARES, 2000).

É, pois, neste sentido, que Powell (2000) defende uma metodologia PBL promotora de parcerias de aprendizagem, quer dentro do grupo em que os aprendentes trabalham, quer com a equipa docente, parcerias estas que, mais tarde, se refletem no relacionamento interpessoal no local de trabalho. O suporte deste processo nas atividades do trabalho em equipa testemunha o aprender a aprender em conjunto. Como resultados desta metodologia, Powell (2000) refere a aquisição de competências a três níveis: técnico (qualidade do trabalho prestado), social (natureza das relações interpessoais) e de autodesenvolvimento (motivação e comunicação). Ou seja, de um ângulo não cognitivo, é suposto que o perfil de um graduado que utilizou metodologias PBL abarque, também, competências sociais e pessoais que a sua vivência profissional, enquanto pessoa e técnico, lhe permite experienciar (HUSSAIN et al., 2007).

Se bem que a implementação de metodologias PBL pareça revelar-se como um instumento eficaz na transição de um cenário teórico para um cenário real e a ligação a problemas profissinais concretos pareça constituir-se como uma mais-valia capaz de prover o estudante de um conjunto de competencias profissionais requeridas pelos empregadores (MUSAL et al., 2003), algumas inquietações podem ser levantadas (e.g. MAJOR e PALMER, 2001). Nomeadamente, como salientam Albanese e Mitchell (1993), sobre a maneira como as metodologias PBL se constituem como capazes de proverem os alunos com construções do conhecimento que os capacite com ferramentas argumentativas sobre as leituras que os mesmos fazem dos problemas reais.

Alguns estudos sobre as metodologias PBL em contexto de simulação empresarial com relevância para a área da contabilidade podem ser consultados. De acordo com as resenhas de Apostolou et al. (2001), Rebele et al. (1998) e Watson et al. (2007) que expõem o estado da arte sobre educação em contabilidade em revistas da especialidade entre 1991 e 2005, apenas três trabalhos se focam na problemática das metodologias PBL. Enquanto Breton (1999) se refere à relação entre conhecimento mais duradouro, melhores resultados obtidos em avaliações finais e alunos PBL, Johnstone e Biggs (1998) sugerem que a metodologia PBL é especialmente adequada para anos terminais dos cursos (onde será possível uma integração mais clara e eficaz dos conhecimentos obtidos anteriormente). Por seu lado, Heagy e Lehmann (2005) observam a 
metodologia como pouco significativa em termos de desempenho nos resultados de avaliação final entre alunos PBL e alunos não envolvidos na metodologia.

Aos estudos referidos, outros trabalhos podem ser adicionados. A título de exemplo, mencionem-se os trabalhos mais recentes de Tate e Grein (2009) ou de Xu e Yang (2010), que mencionam a necessidade de uma maior participação ativa dos estudantes (capaz de permitir a estes criar competências ao nível da resolução criativa de problemas profissionais), ou o impacto positivo das metodologias na construção de modelos mentais mais complexos.

E é precisamente a atenção que parece ser necessária prestar à utilização e aos efeitos de aplicação das metodologias PBL, nomeadamente no âmbito do ensino da contabilidade que, a par com a parca existência de estudos de fundo, nos induz a considerar como objeto de estudo da presente investigação as formas de atuação dos docentes quando inseridos em metodologias PBL.

\section{DESAFIOS DOS DOCENTES EM METODOLOGIAS PBL}

Nos últimos anos, o fenómeno da dissonância entre abordagens tradicionais e abordagens alternativas de ensino tem captado a atenção dos vários atores do processo educativo (e.g. SAVINBADEN, 2003). Tanto quanto ao PBL diz respeito, os docentes têm de ultrapassar dificuldades relacionadas com a responsabilização ativa dos estudantes pelas suas próprias aprendizagens, com a promoção de cenários simulados de situações reais ou com o desenvolvimento de novas técnicas e competências tutoriais.

Como anteriormente referido, na metodologia PBL o papel do professor será o de facilitador, planeando atividades, dialogando, orientando e guiando o aprendente para que, no espaço temporal previsto, o estudante (que aprende ao seu ritmo e inserido num grupo) consiga desenvolver as competências que, ele próprio e o docente, sentiram como objetivos daquela aprendizagem.

De um ponto de vista complementar, Cowan (2000) refere, também, o papel da instrução, sobretudo quando se trata de questões para reavivar a memória de uma dada sequência de passos ou da manipulação de determinado equipamento. No entanto, na sua perspetiva, a resposta à questão do aluno "Como usar isto?" conduzirá a uma aprendizagem mais eficaz se for o próprio a colocá-la, numa linha de aprendizagem auto-orientada e como resultado da expressão das suas necessidades. Paralelamente, Powell (2000) entende o papel do professor não como agente transmissor de um conjunto de conhecimentos, mas sim como facilitador de aprendizagens que respondem às necessidades de determinado trabalho de projeto, sempre com a preocupação de guiar o aluno no seu aprender fazendo, ou, como o autor refere, é mais importante "aprender a aprender do que ensinar sozinho" (POWELL, 2000:36). Particularmente elucidativo do papel de tutor do grupo, é o exemplo referido por Powell (2000) que o compara ao de um treinador (coach). Para este autor, o treinador nem é um jogador nem um líder. Enquanto os jogadores investem a sua energia de uma forma ativa, o treinador observa. De igual forma, a estratégia do docente passa por ver e orientar, mais do que intervir diretamente, por estimular a aprendizagem colocando questões orientadoras e fornecendo pistas, mais do que transmitir conhecimento e fornecer exercícios, por promover pontos intermédios de autoavaliação, mais do que avaliar os resultados finais. Analisando a sua experiência em metodologias PBL, Powell (2000) fala-nos da mudança cultural profunda, implicada pela assunção plena da metodologia. Se, por um lado, o papel do docente pode, à primeira vista, parecer bastante facilitado, por outro, a realidade 
evidencia um intenso trabalho.

Um problema significativo, relacionado com a necessidade de formação dos próprios docentes, é sublinhado por Powell (2000) ao referir-se à função de tutor. De facto, à semelhança de um treinador, sendo os docentes continuamente confrontados com as mais variadas questões, a função de tutor exige novas competências e treino. A experiência de gerir grupos de trabalho, de fomentar diálogo entre os alunos, entre os alunos e o professor ou entre um grupo de professores, que se apoia e entreajuda, tem de ser constantemente construída. Na mesma linha de pensamento, Brockbank e Mcgill (1998) reforçam a necessidade de o professor reconhecer as suas limitações (que se podem traduzir na partilha e busca de respostas dentro de uma equipa de apoio de pares), permitindo ao grupo de estudantes a recolha de uma larga variedade de fontes de informação, incluindo-se, a si próprio, como mais valia do grupo.

Assiste-se, assim, a uma intensa transformação nos papéis dos alunos e dos docentes, competindo aos primeiros assumirem-se como principais responsáveis pelo processo de aprendizagem e, aos segundos, a função de facilitadores, orientadores, motivadores e aferidores da aquisição de competências pelos alunos. Como salientam Hussain et al. (2007) uma mudança estrutural é necessária quando docentes (e estudantes) se envolvem em metodologias PBL, uma vez que se revela essencial desafiar ideias convencionais sobre objetivos, processos de aprendizagem ou métodos de avaliação. Alunos e docentes deixam de se encontrar em planos distintos para se assumirem como agentes ativos e interdependentes.

As relações entre as metodologias PBL enquanto método e objetivo educativo dão lugar a várias questões e muitas apreensões. A assumpção difícil de interiorizar prende-se com o modo de transmissão do conhecimento que coloca o aluno no cerne do sistema e não o docente. Balizados pelos paradigmas apontados parece-nos pois, pertinente, questionarmos quais as reações dos docentes perante os novos desafios que lhes são colocados, especialmente daqueles que se encontram mais enraizados no sistema tradicional de ensino.

Estas alterações às metodologias tradicionais, associadas a papéis ainda não testados e vivenciados pelos atuais docentes, justificam que as práticas propostas aos académicos PBL se apresentem como novos e profundos desafios àqueles que têm a missão de ensinar. Nesta linha de preocupações, interrogamo-nos sobre possíveis resistências à mudança de metodologias de anos e anos de ensino, construídas sob a égide de melhor ensinar e transmitir conhecimentos aos alunos.

\section{O ESTUDO DE CASO DA SIMULAÇÃO EMPRESARIAL}

Como forma de ilustrar a nossa análise e de sustentar o nosso esforço de conceptualização, apoiámo-nos, como instrumento metodológico de trabalho, num estudo de caso único de uma IES profissionalizante, motivado pela disciplina de Simulação Empresarial implementada, desde 1977, no ISCA-UA.

O objetivo genérico desta unidade curricular é o de preparar contabilistas qualificados para trabalharem em ambientes organizacionais, por meio de uma integração aplicada e contextualizada que envolve diferentes temáticas e áreas de atividade, de acordo com os procedimentos das metodologias PBL. Entendida como síntese final, de natureza prática e interativa, dos conhecimentos adquiridos pelos estudantes ao longo do curso, a Simulação Empresarial pretende aproximar os futuros graduados ao contexto empresarial, valorizando 
atitudes, aptidões e competências previamente identificadas com perfis idealizados. Assumindose como uma interface entre o meio académico e o meio profissional, o papel da Simulação Empresarial é o de catalisador motivacional da aprendizagem, num ambiente de simulação que pretende utilizar diferentes áreas de trabalho na promoção de uma perspetiva multidisciplinar. Estrategicamente e por tais razões, a unidade curricular encontra-se colocada no último semestre do plano curricular de estudos.

Na Simulação Empresarial é esperado que os estudantes, organizados em grupos de dois elementos, apliquem a informação e os conhecimentos obtidos nos anos curriculares anteriores, na organização das empresas que ministram e que se encontram inseridas no mercado simulado de empresas virtuais. Todos os alunos são gerentes ou sócios gerentes das empresas que possuem, devendo criar documentos que dão origem a registos contabilísticos e tomar contacto com todo o género de procedimentos com que se irão posteriormente deparar quando realmente integrados em empresas reais. No processo de reprodução precisa da realidade que imitam, é possível às empresas simuladas comprar, vender, pagar, receber, financiar ou recrutar pessoal, cabendo aos próprios alunos os papéis de contabilistas, diretores financeiros, gestores ou técnicos comerciais das suas empresas virtuais, consoante indicações dos docentes responsáveis pela coordenação da unidade curricular. Saliente-se que, o facto de ser o próprio aluno a ter de se introduzir no contexto em que vai decorrer o seu projeto específico, lhe confere um grau de dificuldade mais elevado do que o que seria esperado num estágio numa empresa de base real, uma vez que, neste caso, competiria à mesma o comando de todo o processo.

Sendo a Simulação Empresarial um culminar prático dos conhecimentos adquiridos ao longo do curso, não é indicada uma literatura específica, sendo que os alunos devem já conhecer a bibliografia adequada a cada tema. Pelo contrário, são fornecidas informações concretas de associações profissionais de contabilidade, auditoria ou fiscalidade, bem como sites específicos nas áreas de conhecimento envolvidas. Anualmente, o número de empresas envolvidas ronda as 75. Cada grupo assume-se como empresa ou entidade pública, a quem é sorteada uma determinada atividade económica. Após o sorteio, e a partir de uma informação inicial que indica as linhas genéricas de enquadramento no mercado, cada grupo tem de proceder à constituição (ou reestruturação) da empresa, realizar todas as operações inerentes à respetiva atividade e proceder ao fecho do período económico a que reporta, num espaço temporal correspondente a um ano civil. Em simultâneo, é exigido o cumprimento de todas as operações legais associadas. Procurando simular o mercado empresarial, também o mercado virtual estabelece relações com agentes económicos a montante e a jusante contando, para o efeito, com o apoio de três entidades parceiras: a central comercial, a central financeira e a central pública. Enquanto a primeira enquadra e apoia a implementação da unidade curricular promovendo a dinâmica necessária ao funcionamento dos diversos setores de atividade, a segunda tem o objetivo de assegurar e distribuir um conjunto diversificado de produtos e serviços financeiros. Por último, a central pública desempenha o papel dos vários organismos públicos necessários ao funcionamento legal das empresas.

A preparação da Simulação Empresarial começa durante o semestre letivo imediatamente anterior ao do seu funcionamento. Durante este tempo, os docentes responsáveis pela coordenação da unidade curricular, definem o número e o ramo de empresas a incluir no mercado, assim como as respetivas estruturas relativas ao capital social mínimo, tipo de sociedade, mínimo de investimento, tipo de empresa ou número de trabalhadores. É igualmente competência da equipa de coordenação disponibilizar o regulamento específico da disciplina e definir o cronograma para cada ano letivo. 
Dadas as características específicas da unidade curricular de Simulação Empresarial, esta dispõe de uma sala de trabalho própria, equipada com os recursos informáticos necessários ao seu bom funcionamento. Recorrendo a uma plataforma específica de ensino à distância, toda a comunicação e interatividade operacional de simulação empresarial são feitas recorrendo a um modelo de e-learning. Precedendo o início das atividades operacionais e preparadas pela equipa de coordenação, são ministrados cursos de utilização dos vários programas informáticos disponíveis e promovidas sessões de esclarecimento sobre temas de interesse geral para os alunos inscritos. Para além da equipa docente, são ainda recrutados alguns exalunos da disciplina, designados por monitores. As funções destes monitores são a de coordenar e secretariar as centrais, sendo-lhes definido um horário de trabalho remunerado, por meio de vínculo contratual. Para melhorar o desempenho destes mesmos monitores, mesmo não lhes cabendo qualquer função pedagógica, os mesmos recebem formação prévia quer sobre o software a utilizar quer sobre o modo de funcionamento dos recursos passíveis de utilização pelos alunos.

Vários são os tutores afetos à Simulação Empresarial, competindo a cada um a monitorização de alguns grupos. Sessões semanais entre os tutores permitem uma regulação metodológica global, sendo intento geral que os estudantes assumam um crescente grau de responsabilidade na consecução das suas próprias metas de aprendizagem. A convicção da necessidade de avaliar um amplo conjunto de resultados de aprendizagem conduziu a equipa docente a incluir no processo avaliativo elementos menos palpáveis ao longo de todo o processo (e não apenas enfatizar o resultado final). Assim, orientados por uma avaliação (essencialmente) formativa, os docentes utilizam processos de inspeção regular do trabalho realizado, procurando avaliar quer a capacidade do aluno na resolução dos problemas propostos quer o seu desempenho nas múltiplas tarefas e funções essenciais à obtenção dos objetivos formulados. Assim sendo, os resultados esperados para as aprendizagens dos estudantes abrangem: (1) integração e aplicação de conhecimentos na resolução dos problemas; (2) organização da informação; (3) preparação de relatórios; (4) trabalho de equipa; (5) realização atempada de tarefas; e (6) exposição oral. Para atingir tais objetivos, a avaliação apoia-se em debates quer entre estudantes quer destes com a equipa docente, na observação do trabalho dos alunos, nas auditorias e fiscalizações periodicamente realizadas, nas apresentações e portfolios que se realizam, bem como num vasto conjunto de outros elementos especificados para o efeito.

Saliente-se que, por estar em contraciclo, a adoção de uma metodologia de simulação representou um desafio acrescido e uma mudança substancial tanto para alunos como para docentes. De facto, encontrando-se toda a estrutura metodológica do ISCA-UA organizada segundo modelos tradicionais de ensino, os docentes (e os alunos) envolvidos na Simulação Empresarial são, inesperadamente, expostos a métodos não convencionais de ensino. A título de exemplo, mencione-se a mudança de uma metodologia expositiva para uma metodologia tutorial, ou a mudança de avaliação baseada em exames escritos para uma avaliação contínua baseada em relatórios orais e consecução de objetivos profissionais.

Por fim, refira-se à importância que o modelo PBL adotado pela Simulação Empresarial tem para a Ordem do Técnicos Oficiais de Contas (OTOC) e, por tal facto, o valor acrescido que representa para os futuros graduados (Ordem dos Técnicos Oficiais de Contas, 2010). Sendo a realização de um estágio profissional uma das condições primordiais para acesso à inscrição como técnico oficial de contas, o ISCA-UA é uma das IES dispensadas deste mesmo estágio uma vez que, na visão da OTOC, satisfaz os objetivos que lhe estão inerentes: proporcionar experiência profissional, possibilitar uma maior articulação entre a instituição formadora e o mundo do trabalho e complementar as competências sócio-profissionais dos estudantes. 


\section{OS CONTORNOS METODOLÓGICOS DA INVESTIGAÇÃO}

Com o propósito de explorar a adoção de um curso PBL num ambiente tradicional de ensino, de compreender como os docentes se adaptam a mudanças estruturais e de perceber com que identidades alternativas se confrontam, elegemos o estudo de caso como método de análise qualitativa. O que significa, tal como referem Almeida e Pinto (1995), que o propósito principal é procurar um estudo enérgico em amplitude e profundidade do fenómeno (caso) em estudo. De facto, a opção eleita prende-se, em primeiro lugar, com o objetivo definido para o presente trabalho. Como salientamos na revisão da literatura, as formas de atuação dos docentes envolvidos em metodologias PBL no ensino superior profissionalizante no campo restrito da contabilidade, carecem de uma análise mais rica e profunda. Por outro lado, a escolha de métodos (essencialmente) qualitativos parece-nos igualmente legitimada pelas próprias características das questões de investigação definidas.

Aos argumentos apontados acrescente-se, ainda, que a preferência por um estudo de caso simples resultou, essencialmente, no facto de crermos que o mesmo pode comprovar e completar o conhecimento sobre os aspetos conceptuais envolvidos e de se mostrar uma oportunidade de interesse e divulgação, designadamente ao nível do ensino superior politécnico e, em particular, ao nível dos cursos de contabilidade. Partindo da perspetiva defendida por diversos autores (e.g. BELL, 1998; PARDAL e CORREIA, 1995), num estudo de caso simples a seleção da amostra para análise baseia-se, genericamente, num conjunto de elementos facilitadores de um entendimento alargado do fenómeno, com o fim último de, conjuntamente, assegurar o caráter unitário do mesmo e o seu total entendimento. A estas fundamentações adimos, ainda, a do estudo de caso simples poder constituir-se como um caso piloto de um futuro estudo de casos múltiplos. Foi tendo por base este conjunto de conhecimentos que, atendendo à especificidade do nosso objeto de estudo, fizemos uso de diferentes fontes conceptuais e envolvemos dados relativos às perceções não só dos docentes mas também dos alunos.

$\mathrm{Na}$ recolha da informação optámos pela administração de questionários fechados aos estudantes e pela realização de entrevistas semiestruturadas aos docentes, crentes que estas escolhas seriam as que melhor se ajustavam não só ao tipo de informação que se pretendia perceber como também aos procedimentos operativos de acesso aos vários sujeitos envolvidos. Recorrendo à técnica da entrevista junto dos docentes e à técnica do questionário junto dos alunos, e ao respetivo tratamento, especialmente qualitativo dos dados obtidos (ainda que tenha sido utilizado um conjunto menor de informação estatística), cremos poder compreender muitos dos problemas relacionados com a temática do trabalho.

\subsection{Questionários}

O questionário apresentado aos alunos foi desenhado para compreender as suas posições relativamente a vários aspetos que envolvem a docência, edificando-se como um conjunto de questões estruturadas tematicamente. (Ver Apêndice 1). No primeiro tema foi analisada a perceção dos estudantes sobre a estratégia da equipa docente relativa à forma de orientação na resolução de problemas. O segundo tema centralizou-se em perceber se os académicos mostraram capacidades para clarificar que competências os alunos deviam atingir no final da unidade curricular. Por fim, num terceiro tema, procurou-se conhecer se todos os docentes exprimiram orientações semelhantes durante as sessões tutoriais. A validação dos conteúdos foi 
feita por meio de um questionário piloto ministrado a um grupo representativo de estudantes.

Uma vez ponderadas diversas situações juntamente com a equipa docente quanto à forma de administração do questionário junto dos alunos, optou-se pelo preenchimento não presencial, assumindo-se ser esta a melhor solução, dadas as restrições temporais e a disponibilidade dos sujeitos. A todos os estudantes foi explicado o objetivo do estudo, sendo os alunos convidados a participar. Não sendo o questionário obrigatório e procurando-se que o mesmo traduzisse, o mais fielmente possível, as convicções dos respondentes, o mesmo foi aplicado o mais perto possível do termo da disciplina. O preenchimento foi realizado de forma anónima, tendo sido disponibilizado o período de uma semana para os alunos procederem à sua entrega no cacifo da investigadora. $\mathrm{O}$ questionário foi ministrado aos alunos durante o mês de junho de 2004. Foi utilizada leitura ótica da informação recolhida. Todos os 138 estudantes do curso no momento em que foi realizada a recolha empírica dos dados, foram envolvidos no estudo. Os alunos recolhiam um exemplar do questionário durante uma sessão tutorial, sendo-lhes solicitado o prazo de uma semana para o seu preenchimento. A taxa de retorno dos estudantes foi de $96 \%$ (132 respostas obtidas).

\subsection{Entrevistas}

O estudo empírico respeitante aos docentes baseou-se em entrevistas semiestruturadas desenhadas para apreender os seus pontos de vista, transferindo para o entrevistado um papel mais de informante do que de respondente, no sentido de que o mesmo foi livre de expressar factos e opiniões na sua própria linguagem (LESSARD-HÉBERT et al., 1997). A estruturação dos guiões que serviram de fio condutor às entrevistas assentou no trabalho previamente desenvolvido durante revisão da literatura e nas hipóteses de investigação formuladas. Mais do que estruturas inflexíveis a seguir, os guiões das entrevistas tiveram por base um conjunto de questões abertas, adotadas como pontos de referência capazes de desencadearem os discursos sobre possíveis efeitos da metodologia da disciplina de Simulação Empresarial.

Todas as entrevistas realizadas se iniciaram pela explicação resumida do estudo e dos seus objetivos. Uma vez lançada a questão inicial formulada em termos de objeto do presente estudo e partindo do geral para o particular, as restantes questões (respeitantes às hipóteses gerais e específicas formuladas para o presente trabalho) foram inseridas à medida das oportunidades, embora nem sempre emergissem na linguagem formal com que foram criadas. (Ver Apêndice 2). Refira-se que o guia formulado, para além de facilitar um maior controlo da entrevista, se mostrou vantajoso na circunscrição do ponto de vista do entrevistado. A atenção dada pela investigadora ao risco de pré-estruturação do discurso do entrevistado, bem como o facto de o entrevistado não saber como iria decorrer todo o processo da entrevista permitiu, no nosso entender, minimizar alguns limites ao uso desta técnica de recolha de informação.

No sentido de validar as entrevistas efetuadas, torna-se importante sublinhar, ainda, que foi constante a preocupação da entrevistadora quer em respeitar os tempos de silêncio e o posicionamento verbal e não verbal de uma atitude de escuta, quer em evitar interromper o entrevistado quer em relançar os assuntos em questão. Em termos de validade interna da entrevista, sabedores dos possíveis inconvenientes da mesma (relacionados com a própria organização formal, com as implicações desta na compreensão dos diversos itens e com as modalidades de registo das respostas), entendeu-se ser vantajosa a gravação dos discursos e posterior transcrição dos mesmos. Este facto, a garantia de confidencialidade, o anonimato das informações recolhidas e o consentimento prévio dos entrevistados, pretenderam levar a 
entrevistadora a ganhar a confiança daqueles.

Inteiramente ciente de que a sua própria situação como investigadora poderia influenciar a sua imparcialidade, a entrevistadora apresentou-se como uma figura descomprometida com as vivências da disciplina da Simulação Empresarial, pese embora o simples facto de, ao escolher um determinado conjunto de teorias para quadro conceptual de referência, poder ser identificada a sua forma de pensar.

A estratégia seguida na recolha de informação junto dos docentes, foi a da abordagem informal de cada um, salientando a importância da sua contribuição enquanto elemento envolvido na experiência da Simulação Empresarial, na construção do conhecimento sobre metodologias de ensino-aprendizagem no ensino superior profissionalizante. Dos docentes contactados, apenas um não se mostrou disponível. À exceção de uma entrevista que foi realizada no escritório do entrevistado, a seu pedido, as entrevistas aos docentes foram realizadas, individualmente, no ISCA-UA. As entrevistas aos docentes decorreram durante o mês de março de 2005.

A análise de conteúdo realizada foi construída conjugando um sistema de categorias $a$ priori (identificadas pela revisão da literatura) com alguns ajustamentos empíricos a posteriori, sempre que tal se revelou necessário (MILES e HUBERMAN, 1994). Foi utilizado o software QSR NUD*IST (Non-numerical Unstructured Data Indexing Searching and Theorizing) para o tratamento da informação recolhida.

A definição da amostra dos docentes foi ditada pelas questões a investigar e por restrições de ordem prática. Após observação dos dados respeitantes aos docentes, decidimos incluir na amostra só aqueles com quatro ou mais anos de experiência na Simulação Empresarial. No estudo foram envolvidos catorze docentes. A duração média das entrevistas aos docentes rondou os 41 minutos.

\subsection{A conjugação da abordagem PBL com abordagens tradicionais}

Antes de se proceder à análise dos resultados conseguidos junto dos alunos e docentes, revela-se importante referir que as conclusões retiradas neste estudo devem ser percebidas e avaliadas à luz das metodologias $\mathrm{PBL}$ versus metodologias tradicionais. Na verdade, uma vez que todas as demais unidades curriculares da licenciatura em Contabilidade do ISCA-UA se regem segundo modelos tradicionais de ensino, a abordagem PBL utilizada na Simulação Empresarial aparece isolada dos restantes recursos metodológicos do curso. Consequentemente, quer docentes quer alunos pendem a comparar as experiências PBL experimentadas na Simulação Empresarial com modelos tradicionais de ensino. Nestas circunstâncias, parece-nos possível compaginar a ideia da metodololgia PBL associada à Simulação Empresarial com a ideia de uma metodologia tradicional (entendida no sentido mais socrático do termo), quer entre alunos quer entre docentes.

Assumida que foi esta ideia de fundo, a nossa opção por considerar cada elemento interveniente no estudo como, simultaneamente, elemento de controlo e elemento de análise, permite comparar a perspetiva antes e depois da vivência PBL. Apesar de, tal como referido por Siegel (1975), a opção por uma metodologia em que cada elemento serve para seu próprio controlo se revelar preferível à forma em que se procuram selecionar pares de elementos tão semelhantes quanto possível, estamos cientes de que o método escolhido pode trazer alguns elementos externos, eventualmente, passíveis de serem ponderados. 


\section{CONSEQUÊNCIAS DA UTILIZAÇÃO DE METODOLOGIAS PBL NOS DOCENTES}

Orientados pelos objetivos que serviram de base ao estudo, procurámos perceber e analisar de que forma as metodologias PBL se relacionam com as formas de atuar dos docentes, nomeadamente, na forma como estes de adaptam a mudanças estruturais e com que identidades alternativas se confrontam. Pese embora a utilização nos questionários de escalas de Likert de 5 pontos, e em relação ao tratamento da informação obtida junto dos alunos, a nossa opção procurou agrupar os níveis de resposta orientados na mesma direção. A justificação para tal opção centra-se, essencialmente, na procura de uma interpretação mais compreensível dos dados recolhidos, sem que a mesma possa adulterar, na mínima forma, a intenção de resposta percebida.

\subsection{As perspetivas dos estudantes}

Das respostas dos estudantes parece que os pressupostos teóricos do modelo PBL, pelo menos nos aspetos analisados, não são, de um modo geral, confirmados.

A Tabela 1 regista as considerações dos alunos sobre a estratégia da equipa docente na condução dos problemas.

Tabela 1: Estratégia da equipa docente (forma de orientação)

\begin{tabular}{c|c}
\hline & Percentagem válida \\
\hline Indica uma visão global do caminho a seguir & 57.3 \\
\hline Intervém diretamente na resolução de problemas & 10.7 \\
\hline Indica tanto uma visão global como intervém diretamente & 32.0 \\
\hline
\end{tabular}

Mesmo se a maioria dos estudantes observa que os docentes promoveram a orientação da formação, por meio dos problemas apresentados, em direção aos objetivos planeados, não podemos descurar que $32 \%$ dos alunos reconhece aos académicos um papel versátil, mas ambíguo e híbrido, no processo de integração de modelos tradicionais e de tutoria. Simultaneamente, quase $11 \%$ dos alunos declarou que os docentes simplesmente assumiram um papel tradicional e indicaram, passo a passo, a resolução dos problemas.

Embora acreditemos que esta amplitude de opiniões possa ser uma consequência do facto da Simulação Empresarial se integrar (inesperadamente) num percurso metodológico não tradicional, um ponto interessante é o de que os estudantes sugerem que há diferentes atitudes por parte dos docentes. Mesmo se as perceções dos estudantes denotam diferentes abordagens na forma como aqueles planificam as suas atividades e conduzem as aprendizagens, também indicam que os docentes continuam a assumir formas tradicionais de ensino.

No que respeita aos segundo e terceiro temas analisados, torna-se importante sublinhar que nem a questão de como os académicos abordam as competências que os alunos devem atingir no final da unidade curricular, nem a questão da semelhança de orientações durante a resolução dos problemas, são objeto de uma visão consensual (ver Tabela 2). 
Tabela 2: Estratégia da equipa docente (clarificação e sintonia de orientações)

\begin{tabular}{c|c|c|c}
\hline & $\begin{array}{c}\text { Tendo a discordar } \\
(\%)\end{array}$ & $\begin{array}{c}\text { Nem concordo nem } \\
\text { discordo (\%) }\end{array}$ & $\begin{array}{c}\text { Tendo a } \\
\text { concordar }(\%)\end{array}$ \\
\hline $\begin{array}{c}\text { A equipa docente torna clara as } \\
\text { competências que se pretendem atingir }\end{array}$ & 32.6 & 22.7 & 44.7 \\
\hline $\begin{array}{c}\text { A equipa docente mostra sintonia nas } \\
\text { informações que fornece }\end{array}$ & 49.6 & 19.1 & 31.3 \\
\hline
\end{tabular}

Os resultados evidenciam que, enquanto quase $45 \%$ dos alunos concorda que a estratégia da equipa docente passa por tornar claras quais as competências a conseguir, quase um terço discorda desta mesma afirmação. Portanto, uma observação mais detalhada dos dados revela que, pelo menos um número significativo de alunos manifesta algumas preocupações com a questão.

Mas o maior contraste extraído das respostas dos alunos refere-se à sintonia demonstrada pela equipa docente nas informações que fornece. De facto, enquanto quase metade dos estudantes declara não concordar com a afirmação de que os docentes expressam indicações similares na resolução das questões colocadas, quase um terço proclama a ideia contrária. Esta desconexão levanta outros pontos de discussão. É esperado que os docentes tenham o mesmo entendimento sobre a forma de resolução de um problema profissional? Dão os docentes com experiência profissional na área respostas diferentes daqueles que não são detentores deste tipo de experiência?

\subsection{A perspetiva dos docentes}

A análise qualitativa a que submetemos os dados recolhidos junto dos docentes pode ser organizada em seis grandes temas. A primeira categoria centra-se nos papéis que são propostos aos docentes na Simulação Empresarial. A maioria dos entrevistados perceciona o seu papel principal como um papel de supervisão que possibilita a autonomia do estudante. O comentário seguinte realça esta perceção:

Ou seja, eu nunca respondo, nunca dou uma resposta a determinada dúvida que eles tenham. Normalmente oriento para essa dúvida ou faço-os refletir ao pé de mim e são eles que chegam à resposta. Ou então digo onde é que eles podem pesquisar. E só depois de eles pesquisarem e se debruçarem sobre o assunto e refletirem, é que eventualmente, mais tarde, nós podemos voltar a discutir (...). E nós tentamos não lhe dizer como é que se faz. Dizemos-lhe onde é que ele poderá ir buscar os elementos para resolver aquela questão. (Tutor W)

No entanto, um dos entrevistados revela que nem todos os docentes agem desta forma:

Há aquele professor que gosta de dar receitas e quando eles chegam ao pé deles, eles dizem "Isto é assim, assim e assim." E há outros que dizem "Sim senhor, isto é tudo muito bem. Mas vá ler fulano e vá ler este livro, vá ver aquela informação. E depois venha falar comigo e nós discutimos." Dentro da Simulação Empresarial há posturas diferentes e há diversas formas de encarar as situações. (Tutor S)

Esta observação parece-nos crucial para o entendimento de que há diferentes posturas entre os docentes envolvidos em metodologias PBL. A mesma posição tinha também sido referida pelos alunos. Mas, os académicos também reconhecem que há momentos que requerem atitudes de instrução. Nomeadamente, quando há tópicos que, por uma razão ou por outra, não foram abordados anteriormente. Neste campo, dizem os docentes: 
Ora, se sei que há um determinado tema que não foi abordado, ou que foi mas não muito profundamente noutra disciplina, eu não me sinto muito bem em dizer-lhes que pesquisem aqui, que pesquisem acolá e mais nada. Ainda há poucos dias (...) senti-me na obrigação de lhes dar conceitos genéricos sobre como tratar esse problema. Se me perguntarem “Então mas isso é orientar? Estás a dar uma solução.” Eu neste caso fico na dúvida de como é que hei de proceder. (Tutor F)

Este comentário ilustra uma das questões anteriormente identificadas com os desafios colocados aos docentes: como podem os docentes transmitir conhecimento e um apoio tutorial que promova a aprendizagem? Talvez o papel do docente seja (principalmente) o de facilitador mas o papel tradicional parece, em certos casos, não pode ser abandonado.

Uma outra responsabilidade que os docentes têm de assumir é a da avaliação dos estudantes. Mas mesmo neste campo, os docentes parecem reconhecer diferentes abordagens intrinsecamente relacionadas com instrumentos de retorno. Um dos tutores comenta:

Um aluno fez um teste bom e teve boa nota. Fez um teste mau e teve má nota. Mas a gente não tem a preocupação de chamar o aluno e dizer assim "Olhe, você errou na resolução da alínea a), porque isto era assim e você fez diferente." Na Simulação Empresarial não é assim. Aqui, o docente é avaliador mas com feedback para os alunos. (Tutor $\mathrm{H}$ )

A segunda categoria reflete as preocupações dos académicos com o dilema da dissonância entre uma abordagem tradicional e uma abordagem alternativa. Relativamente a este ponto, um dos entrevistados sublinha:

Havia colegas meus que não iam para a sala. Porque tinham medo de enfrentar os alunos. Porque esta cadeira é completamente diferente. Tem de haver um domínio muito grande de determinadas situações, porque podem aparecer maior diversidade de perguntas. Que é muito mais fácil ir dar uma aula com três exercícios e está a aula feita. Aqui não. Os professores também estão a trabalhar sem rede. (Tutor S)

A terceira categoria está igualmente alinhada com as anteriores. Os académicos declaram que, para além da necessidade de um conhecimento permanentemente atualizado, é fundamental uma forte articulação entre a Simulação Empresarial e outras temáticas lecionadas em disciplinas anteriores:

A Simulação Empresarial é também útil para os professores verificarem a importância que deram a determinados conteúdos e quanto os aprofundaram. Serve para rever a informação que os alunos trazem das disciplinas anteriores. Às vezes mesmo para reformular o que é dado nalgumas disciplinas. (Tutor B)

A quarta categoria incide sobre as mais-valias que uma metodologia PBL pode trazer aos docentes envolvidos. Este parece-nos um ponto de particular interesse, uma vez que não foi ainda isolado no estado da arte das metodologias PBL. Mesmo que os académicos se refiram às metodologias PBL como grandemente desafiadoras, também lhes reconhecem algumas características construtivas. Um dos académicos descreve, desta forma, o mérito de um envolvimento em PBL:

Eu penso que isso foi bom porque tiveram de alargar a sua capacidade de organização (...) ou se calhar tirar dúvidas com os outros docentes, nos livros e penso que isso também fez com que os docentes tivessem que, tal como os alunos, aprofundar os seus conhecimentos. (Tutor P)

Um quinto tema debruçou-se sobre o caráter dual das competências docentes ligadas à existência ou não, de uma experiência profissional. Um dos docentes entrevistados argumenta que:

Há imensa diferença entre um docente com experiência profissional e um docente sem 
experiência profissional. Não podemos dizer que um docente que não tenha experiência profissional não tenha um bom desempenho na Simulação Empresarial. Mas penso que é um bocadinho mais complicado porque na Simulação Empresarial surgem determinadas situações que nós já vivemos. Portanto sei dar muito mais facilmente resposta e orientá-los (...). Um colega que não tenha experiência profissional vai orientá-los apenas naquilo que eles vão questionando. Se calhar, nós vamos dando outra visão daquilo que nós aprendemos. Um colega que não tenha experiência profissional, não significa que não consiga orientar corretamente as questões que eles vão colocando. Talvez não consiga, como não tem experiência, acautelá-los para determinadas situações que possam vir a acontecer. (Tutor E)

Por fim, a sexta categoria, relaciona-se com o perfil de um docente PBL. Na opinião de alguns entrevistados, o ambiente de aprendizagem proposto pela Simulação Empresarial enfatiza a necessidade da identificação dos docentes com o espírito da metodologia. O comentário seguinte traduz esta perceção:

Na Simulação Empresarial tem que haver uma certa vivência disto. É uma cadeira que à partida, as pessoas que vão para lá têm de ir com um espírito de missão. (Tutor S)

Não obstante o facto dos discursos dos académicos sugerirem que o enquadramento metodológico da Simulação Empresarial levanta reais desafios à comunidade docente, é interessante verificar que, entre estas mudanças, os académicos refletem não só sobre as suas próprias preocupações mas também incluem outros docentes não diretamente envolvidos na disciplina.

\section{DISCUSSÃO E CONCLUSÕES}

Uma primeira conclusão significativa apontada por este estudo refere-se não só à capacidade dos académicos para clarificarem que competências os estudantes devem alcançar no final da unidade curricular, mas também à capacidade de os académicos expressarem orientações similares durante a resolução dos problemas propostos. De facto, quando questionados sobre se os docentes transmitiam ou facilitavam o mesmo tipo de informação para o mesmo tipo de problema, metade dos estudantes responderam que não. Enquanto os conceitos teóricos reforçam os papéis de orientação e guia como padrões dos docentes PBL, a presente investigação especificamente indica que os estudantes, não previamente identificados com metodologias que reforcem o seu envolvimento na produção do conhecimento, ainda presumem e esperam respostas pré-formatadas dos docentes.

Um segundo ponto adiantado pelos dados deste estudo revela que as expectativas dos docentes devem ser tidas em linha de conta. Como anteriormente realçado, os currículos das IES profissionalizante incorporam, num mesmo tempo, os conceitos de saber fazer e fazer. Portanto, estes paradigmas parecem legitimar os nossos resultados sobre o potencial das metodologias PBL em fornecerem conhecimento na mesma medida em que este é necessário. Como consequência, o modelo interdisciplinar conceptual apela para uma mútua relação entre os currículos das diversas disciplinas. Ora, tal conduz-nos ao problema de saber como gerir as expectativas dos docentes. De facto, as nossas preocupações voltam-se para a questão de perceber que tipo de abertura os académicos mostram para reconfigurar os seus modelos de ensino, quando as mudanças são sugeridas pelos seus pares. Por outro lado, especulamos se o corpo docente encoraja uma real troca de ideias, quando estas são passíveis de conduzir a mudanças curriculares para as unidades que eles próprios lecionam. Nesta lógica, parece-nos, pois, importante difundir a metodologia PBL entre a comunidade académica, na expectativa de 
tal difusão permita promover um maior conhecimento e compreensão das diferentes dimensões em causa neste processo alternativo de educação e formação.

Uma terceira abordagem confronta-se com a possibilidade de identificação de atitudes diversas entre tutores com e sem experiência profissional. As diferentes perspetivas relacionamse não só com a forma como os docentes orientam os alunos em direção à resolução de um problema, mas também com a forma como os docentes abordam as situações apresentadas nos problemas propostos: enquanto tutores com experiência profissional tendem a lidar com os ambientes PBL de uma forma mais contextualizada e pragmática, tutores sem experiência profissional inclinam-se para soluções mais académicas e conceptuais. Estes resultados permitem adicionar uma peça importante à revisão da literatura efetuada. Se, por um lado, estas inferências dão lugar ao surgimento de algumas questões relativas às vantagens de associar às metodologias PBL sobretudo docentes com experiência profissional, por outro lado, parecem reforçar a importância de se refletir sobre a missão pedagógica das IES. Portanto, a perspetiva que este estudo permitiu assumir, aconselha a discussão relativa às vantagens de introduzir diversos perfis de tutores em ambientes PBL. A reflexão sobre este ponto parece suportar a distinção conceptual entre politécnicos e universidades, levando-nos a acreditar que, em educação profissional, a ligação entre a teoria e a prática tem de ser assumida numa visão integrativa. Mesmo se, em geral, nem docentes com experiência profissional nem docentes sem experiência exibem desempenhos menos adequados, a intenção de uma visão global e pericial parece ser mais enfática entre docentes com prática profissional. Assim sendo, parecenos pertinente explorar o entendimento dos valores estratégicos das experiências profissionais quando confrontados com o poder do saber académico.

Diretamente relacionado com estes problemas, podemos mencionar um quarto tópico familiarizado com os desafios que os docentes PBL enfrentam. O estudo revela que tais desafios determinam preocupações epistemológicas nos tutores. Neste sentido, os docentes referem-se à metodologia PBL como uma metodologia estruturalmente inovadora quando comparada com as atividades de um currículo tradicional. Tal significa que, uma vez envolvidos em metodologias PBL, estudantes e docentes são forçados a desempenhar papéis diferentes dos desempenhados em metodologias tradicionais. Os tutores reconhecem que, apesar de sentirem necessidade de (algumas vezes) assumirem uma postura de docência tradicional, sobretudo necessitam de guiar, de uma forma expedita os estudantes por meio de caminhos de autoaprendizagem. A maior parte dos docentes reconhece que há uma variedade de estratégias na forma como os seus pares lidam com ambientes PBL. Asserções sobre as mudanças decorrentes de um envolvimento em métodos não tradicionais e sobre as reflexões sobre a prática docente são mencionadas por quase todos os tutores. Devido aos diferentes papéis desempenhados pelos estudantes PBL, os docentes vêm-se confrontados com a necessidade de reavaliar as suas ideias sobre as suas próprias práticas. O problema das práticas docentes é um problema importante porque os desafios que lhes são colocados respeitam a diferenças estruturais muito para além das aplicações. De facto, os docentes estão conscientes dos diferentes papéis que precisam de desempenhar mas, mais do que isto, estão conscientes das preocupações epistemológicas que ocorrem quando se fala de aprendizagem em vez de ensino. Na nossa interpretação, tal sugere que o perfil do docente é uma característica importante das metodologias PBL. Como resultado, duas questões se colocam: (1) quais as vantagens de selecionar somente docentes que se identifiquem com as características inovadoras das metodologias PBL; (2) quais as vantagens de envolver docentes identificados com metodologias tradicionais. Por um lado, argumentamos que talvez seja possível encontrar algumas respostas positivas se, ocasionalmente, docentes identificados com perfis tradicionais possam vir a identificar-se com novas posturas metodológicas. Por outro lado, parece-nos sensato não impor grandes mudanças a docentes com uma visão tradicional do 
paradigma do ensino-aprendizagem. Paralelamente, as mesmas razões que desafiam os docentes PBL parecem valer a pena, se não por outras motivos, pelo menos pelo incentivo de desafiar capacidades técnicas e científicas.

Uma quinta preocupação liga-se com os pontos de vista que os estudantes manifestam. Dito de outro modo, parece óbvio refletir sobre os diferentes papéis que se oferecem aos alunos. Nesta lógica, a nossa questão consiste em perceber como é que estudantes desde sempre envolvidos em metodologias tradicionais de ensino reagem a métodos não convencionais. $\mathrm{Na}$ nossa perspetiva, esta inserção pode ser tanto mais difícil quanto mais impositiva. Nesta linha de pensamento, a nossa proposta vai para a explicação da estrutura metodológica do ambiente PBL, não só junto dos docentes mas também junto dos alunos. Parece-nos possível que um maior comprometimento dos estudantes com a produção do seu próprio conhecimento encontre eco na sua consciência sobre as diferentes responsabilidades que enfrentam.

\section{COMENTÁRIOS FINAIS}

Este estudo explora de que forma as mudanças fundamentais que ocorrem emmetodologias emergentes, nomeadamente em metodologias PBL, se refletem sobre os significados de ser docente do ensino superior profissionalizante. Não é intenção deste estudo de caso generalizar resultados. De facto, os dados que analisámos não o permitem. Mais propriamente, o nosso estudo identifica alguns pontos de convergência significativos sobre a ideia do conceito de docente PBL e as consequências sobre os seus comportamentos, expectativas e dúvidas. Por este prisma, os docentes terão de se preparar para repensar e, eventualmente, reformular não só as suas conceptualizações sobre os processos de ensino e aprendizagem, mas também os valores que os suportam.

Argumentamos que uma reflexão metódica e uma reflexão sobre a prática precisam de ser a chave para decisões pedagógicas fundamentadas. Olhando de perto para os papéis atribuídos aos docentes, pensamos que o conceito PBL necessita de uma dupla re(criação) da estrutura metodológica que o suporta. Se os docentes (e os alunos) são preparados para a ideia de que pensamento crítico e argumentação são conceitos fundacionais das metodologias PBL então, talvez, ambos possam valorizar a ideia que as mudanças podem ser benéficas. Mas, tal movimento envolve um maior comprometimento e um risco acrescido da parte dos docentes e da parte dos estudantes. Para diferentes atitudes relativamente a metodologias PBL, docentes (e alunos) precisam de desconstruir os seus papéis tradicionais. Mesmo assim, questionamonos sobre as dificuldades de tal transição. Tal como referem Hussain et al. (2007), os docentes podem oferecer resistência às metodologias PBL se não quiserem ver os seus métodos de ensino verificados.

Manifestamente, o problema de como os académicos se adaptam às metodologias PBL requer uma atenção pedagógica séria da comunidade educativa do ensino superior. Muitas questões ficam por responder. De que forma é que as condições de ensino estão a ser retocadas? Que identidades alternativas para os docentes são possíveis? O que pensam os docentes sobre estas matérias? Quão longe estão os docentes dispostos a ir em defesa de metodologias não tradicionais? Melhores e mais frequentes práticas em PBL podem depender das respostas a estas questões. Se pretendemos um melhor entendimento de como os académicos se procuram adaptar a ambientes PBL, sobretudo no ensino superior profissionalizante, estudos futuros necessitam de ser realizados para replicar e ampliar esta investigação noutros contextos. Como ponto último de reflexão, levantamos a questão da necessidade de serem criadas formas de avaliar, de forma 
sistemática, métodos de ensino e aprendizagem, capazes de ponderarem metodologias cada vez mais sintonizadas com os desafios sociais e tecnológicos da era em que vivemos.

$\mathrm{Na}$ leitura de novas formas de exercício profissional e num pensar epistémico sobre um mundo globalizado, a divulgação da produção científica no ensino, mormemente, em contabilidade, aponta-se como um guião aberto que se pretende desfiado e permanentemente atualizado.

\section{REFERÊNCIAS BIBLIOGRÁFICAS}

ALBANESE, M. A.; MITCHELL, S. Problem-based learning: a review of literature on its outcomes and implementation issues. Journal of the Association of American Medical Colleges, Washington, v. 68, p. 52-81, 1993.

ALMEIDA, J. F.; PINTO, J. M. A investigação nas ciências sociais. Lisboa: Editorial Presença, 1995.

APOSTOLOU, B. A.; WATSON, S. F.; HASSELL, J. M.; WEBBER, S. A. Accounting education literature review (1997 - 1999). Journal of Accounting Education, Youngstown, v. 19, P. 1-61, 2001.

BALLANTINE, J.A.; DUFF, A.; LARRES, P. M. Accounting and business students' approaches to learning: a longitudinal study. Journal of Accounting Education, Youngstown, v. 26, n. 4, p. 188-201, 2008.

BARROWS, H. S. A taxonomy of problem-based learning methods. In: RANKIN, J. (ed.) Handbook on problem-based learning. New York: Forbes Custom Publishing, 1999.

BAYNE, S. Higher Education as a visual practice: seeing through the virtual learning environment. Teaching in Higher Education, Leeds, v. 13, n. 4, p. 395-410, 2007.

BELL, J. Como realizar um projecto de investigação: um guia para a pesquisa em ciências sociais e educação. Lisboa. Gradiva, 1998.

BLIGH, J.; RANKIN, J. Problem-based learning in medicine: an introduction. New York: Forbes Custom Publishing, 1999.

BRETON, G. Some empirical evidence on the superiority of problem-based learning (PBL) method. Accounting Education, Loughborough, v. 8, p. 1-12, 1999.

BROCKBANK, A.; MCGILL, I. Facilitating reflective learning in higher education. Higher Education, Dordrecht, v. 39, p. 489-491, 2000.

COWAN, J. Curriculum development: a booklet to support a staff development workshop. Aveiro: Universidade de Aveiro, 2000.

DAHLGREN, M. A.; OBERG, G. Questioning to learn and learning to question: structure and function of problem-based learning scenarios in environmental science education. Higher Education, Dordrecht, v. 41, p. 263-282, 2001.

GIBBONS, M.; CAMILLE, L.; NOWOTNY, H.; SCHWARTZMAN, S.; SCOTT, P.; TROW, M. The new production of knowledge. London: Sage Publications, 1994.

HEAGY, C. D.; LEHMANN, C. M. Is PBL and improved delivery method for the accounting curriculum? Advances in Accounting Education, Villanova, v. 7, p. 225-251, 2005. 
HUSSAIN, R. M. R.; MAMAT, W. H. W.; SALLEH, N.; SAAT, R. M.; HARLAND, T. Problembase learning in Asian universities. Studies in Higher Education, Lancaster, v. 32, n. 6, p. 761 $772,2007$.

JOHNSTONE, K. M.; BIGGS, S. F. Problem-based learning: introduction, analysis, and accounting curricula implications. Journal of Accounting Education, Youngstown, v. 16, n. 3/4, p. 407-427, 1998.

KIRSCHNER, P.; VILSTEREN, P.; HUMMEL, H.; WIGMAN, M. The design of a study environment for acquiring academic and professional competence. Studies in Higher Education, Lancaster, v. 22, p. 151-171, 1997.

LESSARD-HÉBERT, M. ; GOYETTE, G. ; BOUTIN, G. Recherche qualitative: fondements et pratiques. Montréal : DeBoeck Université, 1997.

MAgalhães, A. A identidade do ensino superior. Política, conhecimento e educação numa época de transição. Braga: Fundação Calouste Gulbenkian, 2004.

MAGALHÃES, A.; AMARAL, A. Portuguese higher education and the imaginary friend: the stakeholders' role in inatitutional governance. European Journal of Education, Paris, v. 35, n. 4, 2000.

MAJOR, C.; PALMER, B. Assessing the effectiveness of problem-based learning in higher education: lessons from the literature. Disponível em http://www.rapidintellect.com/ AEQweb/mop4spr01.htm Acesso em: 23 novembro 2009.

MARGETSON, D. Why is problem based-learning a challenge? In: BOUD, D.; FELETTI, G. (Eds.) The challenge of problem-based learning. London: Kogan Page, 1998.

MILES, M.; HUBERMAN, A. M. Qualitative data analysis. Thousand Oaks: Sage Publications, 1994.

MUSAL, B.; TASKIRAN, C.; KELSON, A. Opinions of tutors and students about the effectiveness of PBL in Dokuz Eylul University School of Medicine. Disponível em http:// www.med-ed-online.org/pdf/f0000073.pdf Acesso em: 23 novembro 2009.

NIJHUIS, J.; SEGERS, M.; e GIJSELAERS, W. The interplay of perceptions of the learning environment, personality and learning strategies: a study amongst International Business Studies students. Studies in Higher Education, Lancaster, v. 32, n. 1, p. 59-77, 2007.

ORDEM DOS TÉCNICOS OFICIAIS DE CONTAS. Lista de cursos reconhecidos com protocolo de dispensa de estágio. 2010. Disponível em $\quad \underline{\mathrm{http}} / / \mathrm{www}$.otoc.pt/gc/?id=294. Acesso em: 11 maio 2010.

PARDAL, L. C. E. Métodos e técnicas de investigação social. Porto: Areal Editores, 1995.

POWELL, P. From classical to project-led education. In: POUZADA, A. S. (ed.) Project Based Learning. Braga: Published by Programme Socrates, 2000.

SAVIN-BADEN, M. Facilitating problem-based learning: illuminating perspectives. Maidenhead: The Society for Research into Higher Education and Open University Press, 2003.

SIEGEL, S. Estatística não paramétrica para as ciências do comportamento. São Paulo: McGraw-Hill de Portugal, 1975.

SILÉN, C.; JUHLIN, L. Self-directed learning - a learning issue for students and faculty. Teaching in Higher Education, Leeds, v. 13, n. 4, p. 461-475, 2008. 
TATE, S. L.; GREIN, B. M. That's the way the cookie crumbles: an attribute sampling application. Accounting Education, Loughborough, v. 18, p. 159-181, 2009.

TAVARES, J. S. R. Ensino superior. (In)sucesso académico. Porto: Porto Editora, 2000.

WATSON, S. F.; APOSTOLOU, B. A.; HASSELL, J. M.; WEBBER, S. A. Accounting education literature review (2003-2005). Journal of Accounting Education, Youngstown, v. 25, p. 1-58, 2007.

XU, Y.; YANG, Y. Student learning in business simulation: an empirical investigation. Journal of Education for Business, Delaware, v. 85, p. 223-228, 2010. 


\section{APÊNDICE 1. ESTRATÉGIA DA EQUIPA DOCENTE}

1. Relativamente à metodologia seguida na disciplina de Simulação Empresarial, com qual das afirmações está mais de acordo? (selecione apenas uma das opções, preenchendo o círculo que melhor exprime a sua opinião)

A equipa docente indica mais uma visão global orientadora do caminho a seguir do que intervem directamente na resolução de problemas.

A equipa docente intervem mais directamente na resolução de problemas do que indica uma visão global orientadora do caminho a seguir.

A equipa docente indica tanto uma visão global orientadora do caminho a seguir como intervem directamente na resolução de problemas.

2. As questões seguintes pretendem avaliar qual o papel da metodologia seguida na disciplina de Simulação Empresarial, nas suas aprendizagens. Cada uma inquire a sua opinião sobre a forma como percepciona as coisas, não existindo respostas certas ou erradas. Com a ajuda da escala a seguir,

\begin{tabular}{|c|c|c|c|c|}
\hline 1 & 2 & 3 & 4 & 5 \\
\hline concordo & concordo parcialmente & $\begin{array}{c}\text { nem concordo } \\
\text { nem discordo }\end{array}$ & discordo parcialmente & discordo \\
\hline
\end{tabular}

indique, para cada questão, o seu grau de concordância ou não concordância com cada uma das afirmações seguintes: (indique o algarismo que melhor se aplica à sua apreciação)

\begin{tabular}{|l|l|}
\hline 3. A equipa docente torna claras as competências que se pretendem atingir & \\
\hline & \\
\hline 4. A equipa docente mostra sintonia nas informações que fornece & \\
\hline
\end{tabular}




\section{APÊNDICE 2. GUIÃO DAS ENTREVISTAS AOS DOCENTES}

\section{Guião da entrevista}

a) Saber que papéis são os docentes chamados a desempenhar;

b) Saber que estratégias específicas são susceptíveis de serem modificadas nas práticas docentes;

c) Saber até que ponto experiências profissionais fora das IES contribuem para desempenhos dissimilares nas actividades pedagógicas dos docentes;

d) Saber se é razoável a identificação de todos os docentes com novas metodologias de ensino.

Hipótese geral: O perfil de um docente envolvido numa metodologia de ensino do tipo PBL em ambientes simulados sofre alterações ao nível das suas práticas de ensino.

Hipótese específica 1: $\mathrm{Na}$ opinião dos docentes, a Simulação Empresarial implementada no ISCA-UA requer docentes portadores de um perfil adequado à situação de ser o aluno o centro do processo de ensino-aprendizagem;

Hipótese específica 2: $\mathrm{Na}$ opinião dos docentes, a Simulação Empresarial implementada no ISCA-UA melhora a atuação dos docentes, tornando mais activas as suas capacidades de organização e gestão.

Questões guia:

- No papel de docente envolvido na equipa de Simulação Empresarial, sinto-me confrontado com a experiência de gerir grupos de trabalho, de fomentar diálogo quer entre os alunos, entre os alunos e o professor ou entre um grupo de professores.

- No papel de docente envolvido na equipa de Simulação Empresarial sinto necessidade de formação específica que me permita lidar com o papel de orientador de todo o processo.

- Como docente, considero que o perfil do futuro graduado que frequentou a disciplina de Simulação Empresarial, inclui não só conhecimentos de base que lhe permitem pesquisar, compreender e interpretar criticamente a literatura existente sobre um dado assunto, mas também inclui a capacidade de comunicar com os outros, verbalmente ou na forma escrita, resolvendo problemas que a sua vivência profissional, enquanto pessoa e técnico, lhe determina. 


\section{ENDEREÇOS DOS AUTORES:}

\section{Margarida M. Pinheiro}

Professora Adjunta

ISCA- Instituto Superior de Contabilidade e Administração

UA - Universidade de Aveiro

Campus Universitário de Santiago - Gabinete 239

3810-193 Aveiro

PORTUGAL

\section{Cláudia S. Sarrico}

Professora Associada com Agregação

Departamento de Gestão

ISEG- Instituto Superior de Economia e Gestão

UTL - Universidade Técnica de Lisboa

Rua Miguel Lupi no 20 - Gabinete 310

1249-078 Lisboa

PORTUGAL

\section{Rui A. Santiago}

Professor Associado com Agregação

DCSPT - Departamento de Ciências Sociais, Políticas e do Território

UA - Universidade de Aveiro

Campus Universitário de Santiago - Gabinete 12.3.30

3810-193 Aveiro

PORTUGAL 